\title{
AVALIAÇÃO DE RISCO OCUPACIONAL EM OBRA DE GRANDE PORTE EM MANUTENÇÃO E CONSERVA DE RODOVIA COM APLICAÇÃO DO FMEA: UMA INVESTIGAÇÃO SOBRE SINALIZAÇÃO E TRABALHO EM RODOVIA
}

\author{
OCCUPATIONAL RISK ASSESSMENT IN LARGE CONSTRUCTION IN MAINTENANCE AND \\ CONSERVATION OF HIGHWAY WITH APPLICATION OF FMEA: AN INVESTIGATION ON SIGNALING \\ AND ROADWORK
}

\author{
Ailda da Luz Lima ${ }^{1}$, Jhelison Gabriel Lima Uchoa ${ }^{2}$, \& André Luís de Oliveira Cavaignac ${ }^{3}$ \\ 123 Universidade CEUMA- Campus Imperatriz ${ }^{13}$ Universidade Federal do Maranhão, Campus Imperatriz. \\ ${ }^{1}$ ailda.luz@ hotmail.com ${ }^{2}$ jhelisong@hotmail.com ${ }^{3}$ andreluiscavaignac@gmail.com
}

\section{ARTIGO INFO.}

Recebido em: 11.12.2020

Aprovado em: 21.05.2021

Disponibilizado em: 22.05.2021

Palavras-Chave: Rodovias, Segurança do Trabalho, Riscos, FMEA.

KEYwORDS: Highways, Occupational Safety, Risks, FMEA.

*Autor Correspondente: Cavaignac, A. L. de O.

\section{RESUMO}

A constante ascensão do modal rodoviário é indiscutível da mesma forma que é o mais representativo na logística de transporte no Brasil. Em decorrência do aumento da utilização desse meio de forma demasiada, a demanda de serviços em obras de construção, manutenção e conserva tem crescido. Essas atividades detêm altos riscos laborais, e a problemática existente com esse crescimento está na segurança do trabalho de quem opera nas vias rodoviárias. Nesse sentido, o objetivo desta pesquisa é realizar uma investigação da situação dos trabalhadores da construção civil em obra de grande porte - manutenção e conserva de rodovia, trecho de Açailândia a Imperatriz-MA, com ênfase nos processos de tapa buraco e limpeza de dispositivos de drenagem. Através dos registros fotográficos foi realizado uma discussão em torno das inconformidades encontradas em comparação às normas regulamentadoras $n^{\circ} 6$ - Equipamentos de Proteção individual (EPI) e $n^{\circ} 18$ - Medidas de Segurança. Subsequentemente, os dados obtidos foram utilizados como prováveis modos de falhas, mediante as situações analisadas para a aplicação do FMEA (failure mode and effect analysis). Com a obtenção do RPN (risk priority number) foi possível organizar os modos de falhas por ordem de prioridade, do mais arriscado ao menos arriscado. Para serviço de limpeza feito com roçadeira manual a falha do sistema de segurança adequado ao equipamento teve o maior RPN de 210, também o maior RPN geral, seguido do modo de falha Acidente de trânsito tendo como causa não-sinalização no trecho da obra obteve o RPN de 108. Portanto, apresenta-se um plano de ações preventivas no sentido de contribuir para mitigar os riscos ocupacionais presentes na obra investigada.
ABSTRACT
The constant rise of the road modal is indisputable in the same way that it is the most representative in transport logistics in Brazil. Due to the increased use of this medium too much, the demand for services in construction, maintenance and conservation works has grown. These activities have high labor risks, and the problem with this growth lies in the safety of the work of those who operate on the roads. In this sense, the objective of this research is to investigate of the situation of construction workers in large construction work - maintenance and conservation of highway, stretch of Açailândia-MA to Imperatriz- MA, with emphasis on the processes of slapping hole and cleaning drainage devices. Through the photographic records, a discussion was conducted about the non-conformities found in comparison to regulatory standards $n^{\circ} 6$ - Personal Protective Equipment (PPE) and $n^{\circ} 18$ - Safety Measures. Subsequently, the data obtained were used as probable modes of failures, through the situations analyzed for the application of FMEA (failure mode and effect analysis). With the obtaining of the RPN (risk priority number) it was possible to organize the failure modes in order of priority, from the riskiest to the least risky. For cleaning service made with a manual brush cutter, the failure of the safety system suitable for the equipment had the highest RPN of 210, also the highest general RPN, followed by the Traffic Accident failure mode with the cause of non- signaling on the stretch of the work obtained 108 $R P N$. Therefore, presents itself a plan of preventive actions in order to contribute to mitigate the occupational risks present in the researched work. 


\section{INTRODUÇÃo}

A constante ascensão do modal rodoviário é visível da mesma forma que é o mais representativo na logística de transporte no Brasil. De acordo com a Confederação Nacional do Transporte (CNT, 2017), é o segmento de maior participação na matriz de transporte de cargas com 61\%, o principal de deslocamento de passageiros e o que mais emprega. $\mathrm{O}$ transporte toneladas úteis (TU) de carga no Brasil aumentou em 29,5\%, passando de 389 milhões em 2006 para 503,8 milhões em 2016, informa o anuário de 2017 da CNT. Em decorrência do aumento da utilização desse meio a demanda de serviços em obras de construção, manutenção e conserva tem crescido. Essas atividades detêm altos riscos laborais, e a problemática existente com esse crescimento está na segurança do trabalho de quem opera nas vias rodoviárias.

Nesse sentido, torna-se pertinente ressaltar que este ofício é considerado um dos mais arriscados do mundo, inclusive no Brasil, líder de taxas de acidentes do trabalho fatais, não fatais e anos de vida perdidos (Santana, 2004). De acordo com Iriart (2008), existem vários fatores para ocorrer acidentes de trabalho nessa área, a saber: os baixos salários dos trabalhadores; a falta de infraestrutura e o descuido dos responsáveis pela segurança nos canteiros de obras; a intensificação do uso da força de trabalho; a desorganização dos coletivos de trabalho e a forma como é organizado o trabalho. Acidentes de trabalho geram custos adicionais à construção civil, principalmente com reparação de danos, indenizações e custos por afastamento de funcionários (Cavaignac \& Forte 2018). Além disso, existem potencias consequências dos acidentes de trabalho, destaca-se que, embora os prejuízos físicos sejam prontamente percebidos, sintomas e transtornos psiquiátricos têm sido cada vez mais observados (Ministério da Saúde do Brasil, 2001). Nesse contexto, o Transtorno de Estresse Pós-Traumático (TEPT) vem sendo apontado como uma das psicopatologias que podem ser desencadeadas após a vivência de um acidente no contexto do trabalho, causando prejuízos e impactos na qualidade de vida dos colaboradores (Bucasio et al., 2005; Buodo et al., 2011; Novara et al., 2009).

Desse modo, busca-se através das concepções de Galon (2011) compreender que a combinação entre trabalho e saúde ainda se deflagra como um paradigma na atualidade. $\mathrm{O}$ autor revela que o modelo da saúde do trabalhador no Brasil permanece em construção, trazendo uma ampla perspectiva do processo de trabalho. De acordo com Salim (2008), a segurança do trabalho busca impulsionar a proteção do trabalhador em seu ambiente de trabalho, com o objetivo de prevenção de acidentes e riscos de trabalho, visando amparo a integridade humana. Nessa continuidade, Peixoto (2016) afirma que acidentes de trabalho implicam em danos sociais imediatos. O ponto mais importante é o comprometimento da saúde e integridade física do trabalhador.

Portanto, os EPIs (Equipamentos de Proteção Individual) são usados pelo trabalhador como uma dentre várias medidas de proteção, as recomendações de uso obrigatório são da NR6. A NR 18.4, a qual trata sobre o Programa de Gerenciamento de Riscos (PGR), mostra que são obrigatórias a elaboração e a implementação do PGR nos canteiros de obras, considerando os riscos ocupacionais e suas medidas protetivas. 
Utiliza-se as ferramentas APR (a análise preliminar de risco), árvore de falha (Fault Tree Analysis- FTA) e FMEA- a análise de modo de falha e efeitos, dos autores Cavaignac \& Forte, 2018; Cavaignac \& Uchoa, 2018; Santos et al., 2019; Dias Júnior \& Cavaignac, 2019; Jorge et al., 2019, pois são as principais para análise de risco. De acordo com Stamatis (2003) o FMEA permite uma classificação de riscos, priorizando os modos de falha conforme um coeficiente chamado número de risco ou RPN. Este número é uma resultante da multiplicação de três índices independentes são eles: severidade (S), ocorrência (O), detecção (D) e variam de 1 a 10, da melhor realidade para a pior. Onde severidade é a classificação que indica a gravidade de uma possível consequência no modo potencial de falha. Gravidade de falha classificada de 1 a 10, advindo de uma consequência sem danos até danos calamitosos ou irreparáveis. A ocorrência no FMEA é a estimativa da frequência ou probabilidade de ocorrência do modo de falha. O método mais eficaz para determinar o seu valor é usando dados reais do processo, todavia, em caso não tenha dados anteriores para realizar essa avaliação podem ser atribuídos escalas qualitativas baseado na experiência dos operadores (Mcdermott et al., 2009).

Nesse sentido, observa-se que nos trabalhos em rodovias há inúmeros riscos e, em muitos casos, a não utilização de diversos equipamentos de proteção coletiva e individual para proteger os funcionários. Este trabalho visa investigar a situação dos trabalhadores da construção civil em obra de grande porte- manutenção e conserva de rodovia, trecho de Açailândia a Imperatriz-MA, com ênfase nos processos de Corte de pavimento asfáltico CBUQ para tapa buraco e limpeza de dispositivos de drenagem e a partir da investigação in loco, realizar a aplicação da ferramenta de análise de risco FMEA (failure mode and effects analysis).

\section{METODOLOGIA}

Essa pesquisa consiste em um estudo de caso, que segundo Carvalho, Duarte, Menezes e Souza (2019), tem como foco um caso específico com o objetivo de conhecer suas causas de modo abrangente e completo. Para Yin, o estudo de caso é considerado o planejamento mais adequado para investigação de um fenômeno contemporâneo em seu contexto real. Desse modo, é justificável a realização de um estudo de caso "se o caso se constituir em um evento raro ou exclusivo ou se servir a um propósito revelador" (Yin, 2001).

O estudo foi realizado em uma obra de manutenção e conserva de rodovia com extensão de 67,6 km, entre Açailândia e o município de Imperatriz. Trecho esse localizado do KM 319 a KM 251. Nele foram verificadas duas equipes in loco, cada uma com 20 colaboradores trabalhando ao longo do trecho. No momento do estudo em campo, as atividades realizadas pelas equipes eram as seguintes, a seguir: tapa buraco e limpeza de dispositivos de drenagem. Ademais, foi feito a observação in loco da situação dos colaboradores e apontado por meio de fotografias. Através desses registros fotográficos foi realizado uma discussão em torno das inconformidades encontradas em relação ao risco ocupacional de acordo com o estabelecido nas normas regulamentadoras $n^{\circ} 6-$ Equipamentos de Proteção individual (EPI) e $\mathrm{n}^{\circ} 18$ Medidas de Segurança. 
Subsequentemente, os dados obtidos foram utilizados como prováveis modos de falhas, mediante as situações analisadas para a aplicação do FMEA. Foram elaboradas tabelas do FMEA para cada processo, elencando um modo de falha, causas, efeitos, métodos de detecção, ações preventivas e a construção do RPN (número de prioridade de risco - Risk Priority Number). Após isto, foi possível uma comparação entre as situações menos arriscadas e mais arriscadas, tendo a última a necessidade de ações preventivas imediatas e priorização de risco. Mediante isso, foi produzido um plano de ações preventivas. As ferramentas utilizadas para a análise de risco foram a seguintes: a análise preliminar de risco APR; árvore de falha (Fault Tree Analysis- FTA) e a análise de modo de falha e efeitos FMEA (Uchoa et al., 2019; Cavaignac \& Forte, 2018; Cavaignac \& Uchoa, 2018; Santos et al., 2019; Dias Júnior \& Cavaignac, 2019; Jorge et al., 2019).

Na Tabela 1, pode-se verificar o modelo proposto por Cavaignac e Uchoa (2018), como ferramenta de referência aos profissionais que elaboram, executam e pesquisam sobre o tema de segurança do trabalho e reforçado por Cavaignac e Forte (2018), tem como intuito facilitar a utilização do FMEA relatador por Laurenti et al. (2012).

Tabela 1. Tabela de referência de índices de Severidade (S), Ocorrência (O) e Detecção (D)

\begin{tabular}{|c|c|c|c|c|c|}
\hline & Severidade (S) & & Ocorrência $(\mathrm{O})$ & & Detecção (D) \\
\hline Índice & $\begin{array}{l}\text { Natureza da } \\
\text { severidade }\end{array}$ & Índice & $\begin{array}{c}\text { Natureza da } \\
\text { ocorrência }\end{array}$ & Índice & $\begin{array}{c}\text { Natureza de } \\
\text { detecção }\end{array}$ \\
\hline 1 & Sem impacto real & 6 & Impacto sofrido & 1 & \\
\hline 2 & Trauma irrelevante & 5 & $\begin{array}{l}\text { Queda com } \\
\text { diferença de } \\
\text { Nível }\end{array}$ & 2 & $\begin{array}{l}\text { Inspeção } \\
\text { visual }\end{array}$ \\
\hline 3 & $\begin{array}{l}\text { Trauma que requer } \\
\text { primeiros socorros }\end{array}$ & 5 & Impacto contra & 3 & $\begin{array}{l}\text { Teste tátil / } \\
\text { teste manual }\end{array}$ \\
\hline 4 & $\begin{array}{l}\text { Incapacidade temporária } \\
\text { sem afastamento }\end{array}$ & 5 & $\begin{array}{c}\text { Esforço } \\
\text { excessivo ou } \\
\text { Inadequado }\end{array}$ & 4 & \\
\hline 5 & $\begin{array}{l}\text { Incapacidade temporária } \\
\text { com afastamento curto }\end{array}$ & 5 & $\begin{array}{l}\text { Prensagem ou } \\
\text { Aprisionamento }\end{array}$ & 5 & \\
\hline 6 & $\begin{array}{l}\text { Incapacidade temporária } \\
\text { com afastamento longo }\end{array}$ & 5 & $\begin{array}{l}\text { Queda em } \\
\text { mesmo nível }\end{array}$ & 6 & Aplicação de \\
\hline 7 & $\begin{array}{c}\text { Incapacidade } \\
\text { permanente parcial }\end{array}$ & 4 & $\begin{array}{l}\text { Exposição ao } \\
\text { Ruído }\end{array}$ & 7 & $\begin{array}{c}\text { checklist / } \\
\text { sequência } \\
\text { de testes antes } \\
\text { da tarefa }\end{array}$ \\
\hline 8 & $\begin{array}{l}\text { Incapacidade } \\
\text { permanente total }\end{array}$ & 4 & $\begin{array}{c}\text { Exposição ao } \\
\text { Ruído } \\
\text { Nociva }\end{array}$ & 8 & $\begin{array}{c}\text { Inspeção } \\
\text { instrumental }\end{array}$ \\
\hline 9 & $\begin{array}{c}\text { Óbito de envolvidos } \\
\text { no processo }\end{array}$ & 4 & Choque elétrico & 9 & $\begin{array}{c}\text { Testes } \\
\text { mecânicos }\end{array}$ \\
\hline 10 & $\begin{array}{l}\text { Óbito de não } \\
\text { envolvidos no processo }\end{array}$ & 3 & $\begin{array}{l}\text { Atrito ou } \\
\text { Abrasão }\end{array}$ & 10 & $\begin{array}{c}\text { Ausências de } \\
\text { métodos } \\
\text { efetivos }\end{array}$ \\
\hline- & - & 3 & $\begin{array}{c}\text { Contato com } \\
\text { Temperatura } \\
\text { Extrema }\end{array}$ & - & - \\
\hline
\end{tabular}

Fonte: Cavaignac e Uchoa, 2018. 
Para a aplicação do FMEA em SSo foi utilizado o modelo usado por Uchoa, et al (2019). A tabela 2 mostra o modelo utilizado para a aplicação do FMEA neste trabalho.

Tabela 2. Modelo de tabela para aplicação do FMEA em análise de risco ocupacional.

\begin{tabular}{|c|c|c|c|c|c|c|}
\hline $\begin{array}{l}\text { Tipo da } \\
\text { Falha }\end{array}$ & $\begin{array}{l}\text { Potencial Modo de } \\
\text { Falha }\end{array}$ & $\begin{array}{l}\text { Potencial Causa da } \\
\text { Falha }\end{array}$ & 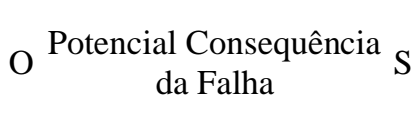 & $\begin{array}{l}\text { Medida } \\
\text { de } \\
\text { Controle }\end{array}$ & D RPN & $\begin{array}{c}\text { Ações } \\
\text { Preventivas }\end{array}$ \\
\hline
\end{tabular}

Fonte: Uchoa et al., (2019). Adaptado.

\section{INCONFORMIDADES ENCONTRADAS NA OBRA}

Com base nos registros fotográficos obtidos pelos autores durante a abordagem do processo in loco, foi possível constatar um grupo de inconformidades, ressaltando as irregularidades quanto ao não cumprimento das NR 6 e NR 18. As figuras apresentadas abaixo pontuam cada inconformidade.

Figura 1. Inconformidades encontradas no trabalhador [1]: ausência de (a) luvas, (b) caneleira, (c) vestimentas para proteção do tronco e (d) local de trabalho sem sinalização

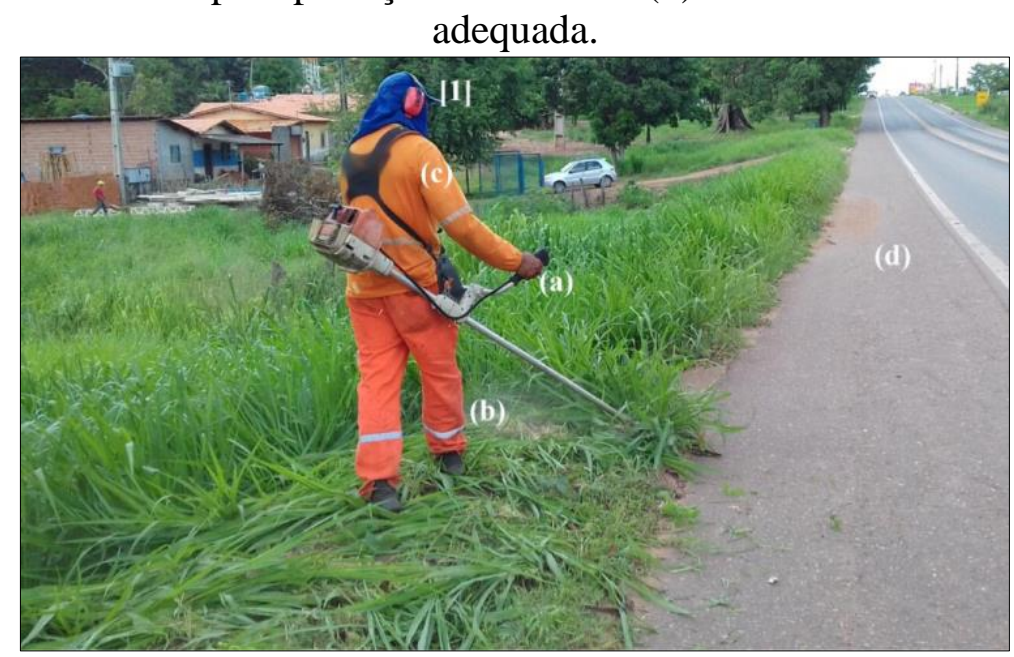

Fonte: Autores, 2020.

A ausência de EPIs foi registrada em diversos momentos do estudo, comprometendo assim a saúde do trabalhador, vê-se a seguir nas figuras 1, 2, 3 e 4. Observa-se nas figuras 1 e 2 o não uso de um equipamento básico de proteção que são as luvas. Conforme registra a norma regulamentadora $\mathrm{N}^{\circ} 6$ luvas têm intuito de proteção das mãos contra vibrações e proteção contra agentes químicos. Na figura 1 , pode-se identificar a ausência de perneira e vestimentas apropriadas, a NR N 6 no anexo 1 mostra que a perneiras essencial para a proteção da perna contra agentes cortantes e perfurantes e a vestimentas tal como avental são para proteção do tronco contra riscos de origem mecânica.

Quanto a NR $N^{\circ} 18$ sessão 22.3 as máquinas e os equipamentos que ofereçam risco de ruptura de suas partes móveis, projeção de peças ou de partículas de materiais devem ser providos de proteção adequada. Já na NR No 18.23.1 deixa claro que a empresa é obrigada a fornecer aos trabalhadores, gratuitamente, EPI adequado ao risco e em perfeito estado de conservação e funcionamento, consoante as disposições contidas na NR 6 - Equipamento de Proteção Individual - EPI.

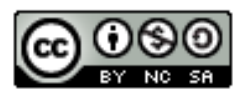


Figura 2. Inconformidades encontradas nos trabalhadores [1] e [2]: ausência de (a) luvas, (b) vestimentas para proteção do tronco (c) capuz ou balaclava (d) mascaras.

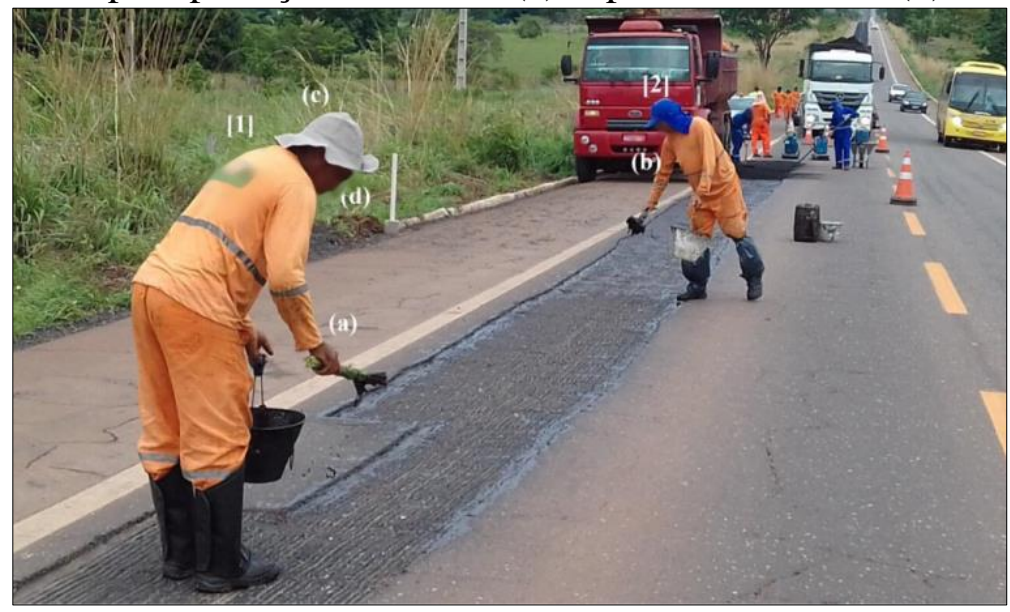

Fonte: Autores, 2020.

De acordo com a NR $\mathrm{N}^{\circ} 6$ a figura 2 contém inconformidades, de uso indispensável as luvas são para proteção das mãos contra agentes químicos, capuz ou balaclava para proteção do crânio e pescoço contra riscos de origem térmica; face e pescoço contra agentes químicos, vestimentas para proteção do tronco contra agentes químicos.

Figura 3. Inconformidades encontradas nos trabalhadores [1] e [2]: ausência de (a) balaclava, (b) luvas, (c) protetor auditivo.

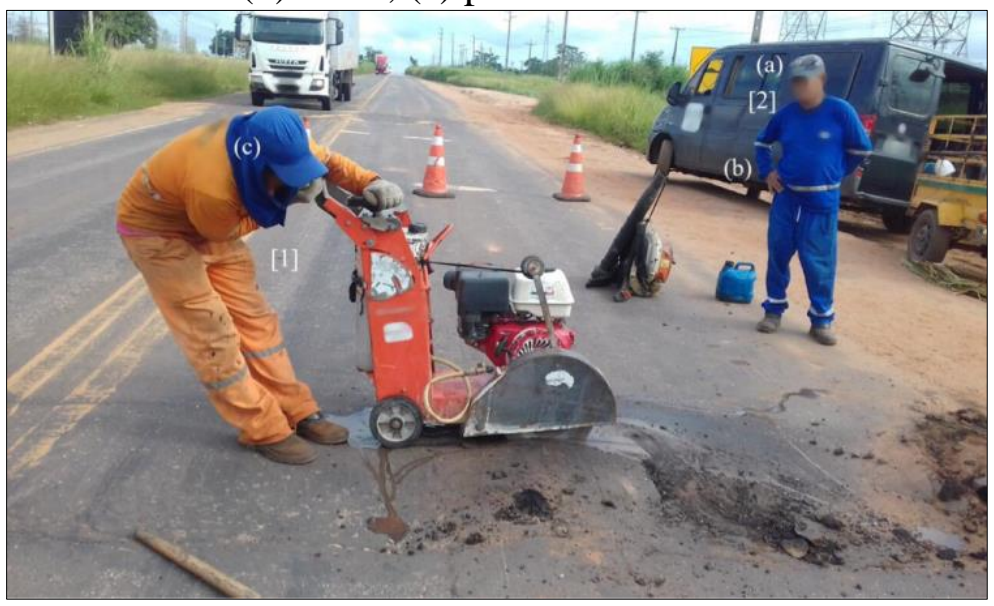

Fonte: Autores, 2020.

Na Figura 3 pode-se observar que o trabalhador [1] não utiliza protetor auditivo, de acordo com a NR $N^{\circ} 6$ protetor auditivo circum-auricular para proteção do sistema auditivo contra níveis de pressão sonora. Mediante a NR No 18 no tópico 22.1A operação de máquinas e equipamentos que exponham o operador ou terceiros a riscos só pode ser feita por trabalhador qualificado e identificado por crachá. Trabalhador [2] em atitude insegura, colocando-se em situação de risco. O colaborador em questão está em pé próximo ao local onde está sendo executado um serviço e não exercia nenhuma função no momento, estava observando um colega, porém em uma posição perigosa. Aliado ao fato, o colaborador não utilizava os EPIs necessários, como protetor auditivo, balaclava e luvas.

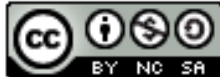


Figura 4. Inconformidades encontradas nos trabalhadores [1]: ausência de (a) balaclava, (b) local de trabalho sem sinalização adequada.

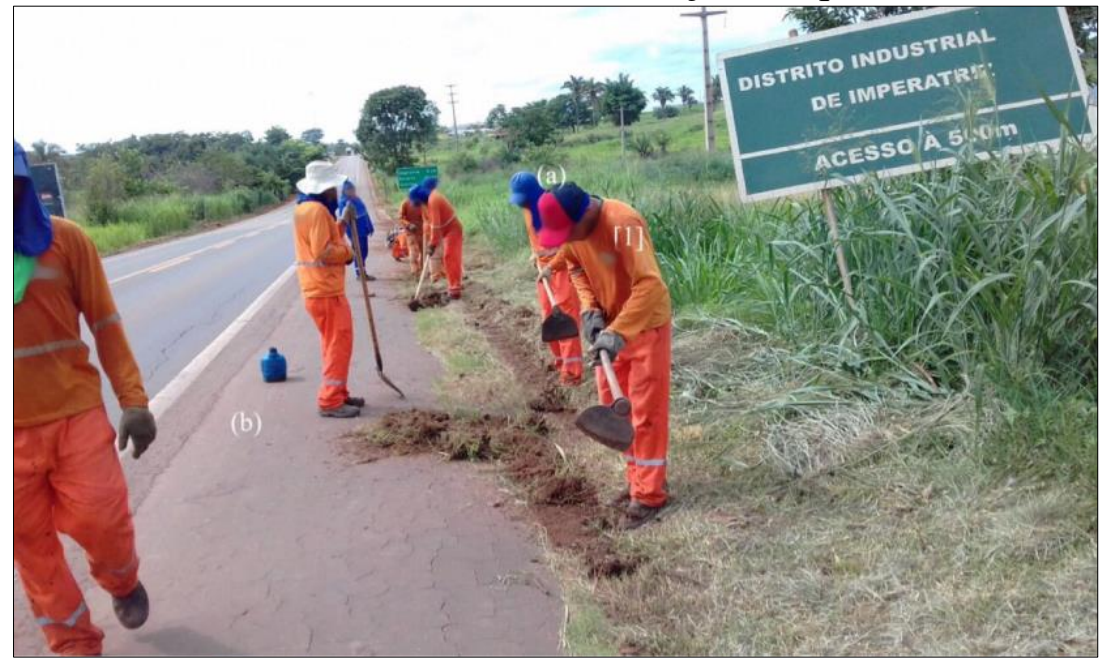

Fonte: Autores, 2020.

Quanto a NR $N^{\circ} 18$ tópico 27.1, várias inconformidades são observadas, O canteiro de obras não está sinalizado. A NR $N^{\circ} 18$ registra que o canteiro de obras deve ser sinalizado com o objetivo: a) identificar os locais de apoio que compõem o canteiro de obras; b) manter comunicação através de avisos, cartazes ou similares.

Ainda de acordo com a NR N 18 tópico 27.3 é obrigatório o uso de sinalização de segurança em vias públicas deve ser dirigida para alertar os motoristas, pedestres e em conformidade com as determinações do órgão competente.

\section{APLICAÇÃO DO FMEA}

As tabelas a seguir apresentam uma aplicação do FMEA a partir de dados coletados in loco em três processos: Limpeza de dispositivos de drenagem com roçadeira manual, correção da pavimentação e corte de pavimento asfáltico. Após as tabelas será realizada uma discussão dos resultados alcançados.

Tabela 3. Aplicação do FMEA na limpeza com roçadeira manual.

\begin{tabular}{|c|c|c|c|c|c|c|c|c|c|}
\hline $\begin{array}{l}\text { Tipo da } \\
\text { Falha }\end{array}$ & $\begin{array}{c}\text { Potencial Modo } \\
\text { de Falha }\end{array}$ & $\begin{array}{c}\text { Potencial } \\
\text { Causa da } \\
\text { Falha } \\
\end{array}$ & $\mathbf{O}$ & $\begin{array}{c}\text { Potencial } \\
\text { Consequência } \\
\text { da Falha } \\
\end{array}$ & $\mathbf{S}$ & $\begin{array}{l}\text { Medida } \\
\text { de } \\
\text { Controle }\end{array}$ & D & $\begin{array}{c}\mathbf{R P} \\
\mathbf{N}\end{array}$ & $\begin{array}{c}\text { Ações } \\
\text { Preventivas }\end{array}$ \\
\hline $\begin{array}{l}\text { Ausência de } \\
\text { Sinalização }\end{array}$ & $\begin{array}{l}\text { Acidente de } \\
\text { Trânsito }\end{array}$ & $\begin{array}{l}\text { Impacto } \\
\text { Sofrido }\end{array}$ & 6 & $\begin{array}{l}\text { Morte dos } \\
\text { envolvidos no } \\
\text { processo }\end{array}$ & 9 & Visual & 2 & 108 & $\begin{array}{l}\text { Checagem } \\
\text { adequada do } \\
\text { ambiente de } \\
\text { trabalho }\end{array}$ \\
\hline $\begin{array}{l}\text { Equipamento } \\
\text { com } \\
\text { manutenção } \\
\text { irregular }\end{array}$ & $\begin{array}{c}\text { Falha do sistema } \\
\text { de segurança } \\
\text { adequado ao } \\
\text { equipamento }\end{array}$ & $\begin{array}{l}\text { Impacto } \\
\text { Sofrido }\end{array}$ & 6 & $\begin{array}{c}\text { Incapacidade } \\
\text { permanente } \\
\text { parcial }\end{array}$ & 7 & Checklist & 5 & 210 & $\begin{array}{l}\text { Checagem da } \\
\text { fixação dos } \\
\text { aparatos de } \\
\text { segurança } \\
\text { anteriormente } \\
\text { a utilização do } \\
\text { equipamento }\end{array}$ \\
\hline $\begin{array}{c}\text { Ausência de } \\
\text { EPI }\end{array}$ & $\begin{array}{l}\text { Impacto causado } \\
\text { por detritos em } \\
\text { relação a } \\
\text { ausência da }\end{array}$ & $\begin{array}{l}\text { Impacto } \\
\text { Sofrido }\end{array}$ & 6 & $\begin{array}{l}\text { Incapacidade } \\
\text { temporária com } \\
\text { afastamento } \\
\text { curto }\end{array}$ & 5 & Visual & 1 & 30 & $\begin{array}{c}\text { Uso adequado } \\
\text { do EPI }\end{array}$ \\
\hline
\end{tabular}




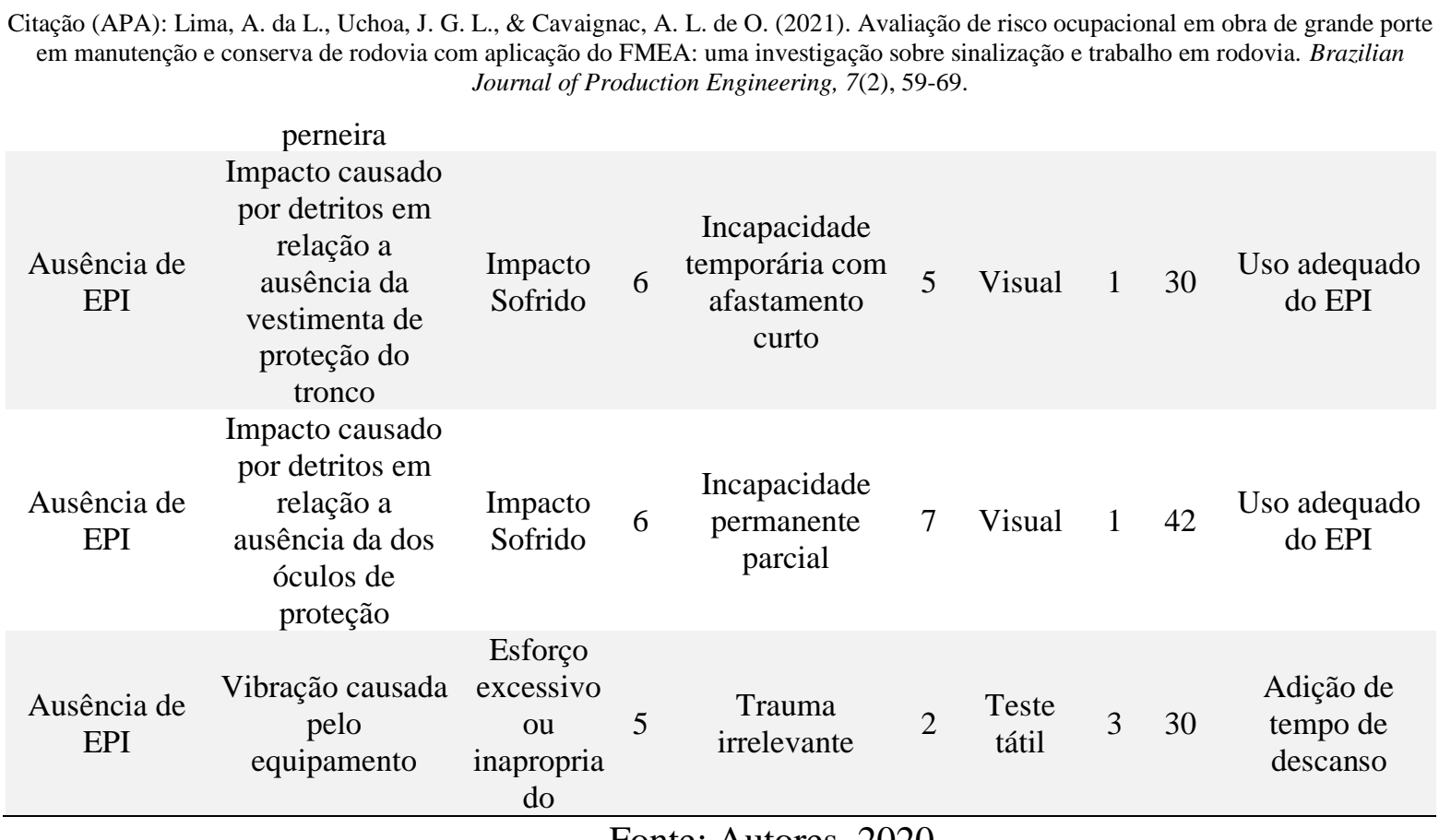

Fonte: Autores, 2020.

$\mathrm{Na}$ Tabela 3 sobre limpeza com roçadeira manual, tem-se falhas acerca da ausência de sinalização do ambiente de trabalho, equipamentos com manutenção irregular e ausências de EPI. A ausência de sinalização pode acarretar em um acidente de trânsito, levando até a morte dos envolvidos no processo. Está é uma falha com medida de controle visual.

Caso a roçadeira manual não seja verificada antes de sua utilização, a mesma pode causar a incapacidade permanente parcial do usuário por conta de suas lâminas. A checagem deste equipamento pode ser feita por um checklist que leve em consideração seus aparatos de segurança. As falhas seguintes discorrem a respeito da ausência dos EPIS obrigatórios durante a execução da atividade.

Tabela 4. Aplicação do FMEA na correção da pavimentação.

\begin{tabular}{|c|c|c|c|c|c|c|c|c|c|}
\hline $\begin{array}{l}\text { Tipo da } \\
\text { Falha }\end{array}$ & $\begin{array}{c}\text { Potencial Modo } \\
\text { de Falha }\end{array}$ & $\begin{array}{l}\text { Potencial } \\
\text { Causa da } \\
\text { Falha }\end{array}$ & $\mathbf{O}$ & $\begin{array}{c}\text { Potencial } \\
\text { Consequência } \\
\text { da Falha }\end{array}$ & $\mathbf{S}$ & $\begin{array}{l}\text { Medida } \\
\text { de } \\
\text { Controle }\end{array}$ & D & RPN & $\begin{array}{c}\text { Ações } \\
\text { Preventivas }\end{array}$ \\
\hline $\begin{array}{c}\text { Ausência de } \\
\text { EPI }\end{array}$ & $\begin{array}{c}\text { Contato com } \\
\text { agentes químicos } \\
\text { pela ausência de } \\
\text { luva }\end{array}$ & $\begin{array}{l}\text { Contato } \\
\text { com } \\
\text { substancia } \\
\text { perigosa }\end{array}$ & 4 & $\begin{array}{l}\text { Incapacidade } \\
\text { temporária sem } \\
\text { afastamento }\end{array}$ & 4 & Visual & 1 & 16 & $\begin{array}{c}\text { Uso } \\
\text { adequado do } \\
\text { EPI }\end{array}$ \\
\hline $\begin{array}{c}\text { Ausência de } \\
\text { EPI }\end{array}$ & $\begin{array}{l}\text { Insolação } \\
\text { causado pela } \\
\text { ausência de } \\
\text { balaclava }\end{array}$ & $\begin{array}{c}\text { Esforço } \\
\text { excessivo } \\
\text { ou } \\
\text { inapropriado }\end{array}$ & 5 & $\begin{array}{l}\text { Incapacidade } \\
\text { temporária sem } \\
\text { afastamento }\end{array}$ & 4 & Visual & 1 & 20 & $\begin{array}{c}\text { Uso } \\
\text { adequado do } \\
\text { EPI }\end{array}$ \\
\hline $\begin{array}{c}\text { Ausência de } \\
\text { EPI }\end{array}$ & $\begin{array}{c}\text { Intoxicação } \\
\text { causada pela } \\
\text { ausência de } \\
\text { mascaras }\end{array}$ & $\begin{array}{l}\text { Contato } \\
\text { com } \\
\text { substancia } \\
\text { perigosa }\end{array}$ & 4 & $\begin{array}{l}\text { Incapacidade } \\
\text { temporária sem } \\
\text { afastamento }\end{array}$ & 4 & Visual & 1 & 16 & $\begin{array}{c}\text { Uso } \\
\text { adequado do } \\
\text { EPI }\end{array}$ \\
\hline
\end{tabular}

Fonte: Autores, 2020.

Na Tabela 4, durante a correção da pavimentação, os trabalhadores entravam em contato com substancias químicas. Por conta disso a utilização de EPI's é essencial para a atividade. Por mais que as consequências imediatas, assim como demonstrado no FMEA, sejam leves, a desconsideração a longo prazo pode causar danos irreparáveis a saúde dos trabalhadores.

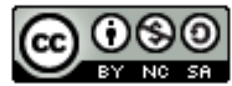



em manutenção e conserva de rodovia com aplicação do FMEA: uma investigação sobre sinalização e trabalho em rodovia. Brazilian Journal of Production Engineering, 7(2), 59-69.

Tabela 5. Aplicação do FMEA no corte de pavimento asfáltico.

\begin{tabular}{|c|c|c|c|c|c|c|c|c|c|}
\hline $\begin{array}{c}\text { Tipo da } \\
\text { Falha }\end{array}$ & $\begin{array}{l}\text { Potencial } \\
\text { Modo de } \\
\text { Falha } \\
\end{array}$ & $\begin{array}{c}\text { Potencial } \\
\text { Causa da } \\
\text { Falha } \\
\end{array}$ & O & $\begin{array}{c}\text { Potencial } \\
\text { Consequência } \\
\text { da Falha } \\
\end{array}$ & $\mathbf{S}$ & $\begin{array}{c}\text { Medida } \\
\text { de } \\
\text { Controle } \\
\end{array}$ & D & RPN & $\begin{array}{c}\text { Ações } \\
\text { Preventivas }\end{array}$ \\
\hline $\begin{array}{l}\text { Ausência de } \\
\text { Sinalização }\end{array}$ & $\begin{array}{c}\text { Local de } \\
\text { trabalho } \\
\text { frequentado por } \\
\text { terceiros }\end{array}$ & $\begin{array}{l}\text { Impacto } \\
\text { Sofrido }\end{array}$ & 6 & $\begin{array}{l}\text { Incapacidade } \\
\text { permanente }\end{array}$ & 8 & Visual & 2 & 96 & $\begin{array}{l}\text { Checagem } \\
\text { adequada do } \\
\text { ambiente de } \\
\text { trabalho }\end{array}$ \\
\hline $\begin{array}{c}\text { Ausência de } \\
\text { EPI }\end{array}$ & $\begin{array}{c}\text { Vibração } \\
\text { causado pelo } \\
\text { equipamento }\end{array}$ & $\begin{array}{c}\text { Esforço } \\
\text { excessivo } \\
\text { ou } \\
\text { inapropriado }\end{array}$ & 5 & $\begin{array}{c}\text { Trauma } \\
\text { irrelevante }\end{array}$ & 2 & $\begin{array}{l}\text { Teste } \\
\text { tátil }\end{array}$ & 3 & 30 & $\begin{array}{l}\text { Adição de } \\
\text { tempo de } \\
\text { descanso }\end{array}$ \\
\hline $\begin{array}{c}\text { Ausência de } \\
\text { EPI }\end{array}$ & $\begin{array}{c}\text { Insolação } \\
\text { causado pela } \\
\text { ausência de } \\
\text { balaclava }\end{array}$ & $\begin{array}{c}\text { Esforço } \\
\text { excessivo } \\
\text { ou } \\
\text { inapropriado }\end{array}$ & 5 & $\begin{array}{l}\text { Incapacidade } \\
\text { temporária sem } \\
\text { afastamento }\end{array}$ & 4 & Visual & 1 & 20 & $\begin{array}{c}\text { Uso adequado } \\
\text { do EPI }\end{array}$ \\
\hline $\begin{array}{c}\text { Ausência de } \\
\text { EPI }\end{array}$ & $\begin{array}{c}\text { Audição } \\
\text { prejudicada } \\
\text { pela ausência } \\
\text { do protetor } \\
\text { auditivo }\end{array}$ & $\begin{array}{l}\text { Exposição } \\
\text { ao ruído }\end{array}$ & 4 & $\begin{array}{l}\text { Incapacidade } \\
\text { temporária sem } \\
\text { afastamento }\end{array}$ & 4 & Visual & 1 & 16 & $\begin{array}{c}\text { Uso adequado } \\
\text { do EPI }\end{array}$ \\
\hline
\end{tabular}

Fonte: Autores, 2020.

O local de trabalho frequentado por terceiros, como visto na tabela 5, por causar até a incapacidade permanente, levante em consideração que o mesmo não estaria utilizando os EPI's aplicados ao trabalho de corte de pavimento asfáltico.

A partir da identificação e priorização dos riscos, a ferramenta FMEA (failure mode and effects analysis) foi utilizada para analise causas modo de falha e efeito dos processos em relação aos riscos quantificando-os. Na Tabela 6 contém um plano de ações preventivas no sentido de contribuir para mitigar os riscos ocupacionais presentes na obra investigada.

Tabela 6. Plano de ações preventivas, com sugestões para correções dos modos de falha com suas prioridades de acordo com RPN.

\begin{tabular}{|c|c|c|c|c|}
\hline $\begin{array}{l}\text { Ordem de } \\
\text { prioridade }\end{array}$ & Tipo da Falha & $\begin{array}{c}\text { Potencial Modo de } \\
\text { Falha }\end{array}$ & RPN & Ações Preventivas \\
\hline $1^{\circ}$ & $\begin{array}{l}\text { Equipamento com } \\
\text { manutenção irregular }\end{array}$ & $\begin{array}{l}\text { Falha do sistema de } \\
\text { segurança adequado } \\
\text { ao equipamento }\end{array}$ & 210 & $\begin{array}{c}\text { Checagem da fixação dos aparatos de } \\
\text { segurança anteriormente a utilização } \\
\text { do equipamento }\end{array}$ \\
\hline $2^{\circ}$ & $\begin{array}{l}\text { Ausência de } \\
\text { Sinalização }\end{array}$ & Acidente de trânsito & 108 & $\begin{array}{c}\text { Checagem adequada do ambiente de } \\
\text { trabalho }\end{array}$ \\
\hline $3^{\circ}$ & $\begin{array}{l}\text { Ausência de } \\
\text { Sinalização }\end{array}$ & $\begin{array}{l}\text { Local de trabalho } \\
\text { frequentado por } \\
\text { terceiros }\end{array}$ & 96 & $\begin{array}{l}\text { Checagem adequada do ambiente de } \\
\text { trabalho }\end{array}$ \\
\hline $4^{\circ}$ & Ausência de EPI & $\begin{array}{l}\text { Impacto causado por } \\
\text { detritos em relação a } \\
\text { ausência da dos óculos } \\
\text { de proteção }\end{array}$ & 42 & Uso adequado do EPI \\
\hline $5^{\circ}$ & Ausência de EPI & $\begin{array}{l}\text { Impacto causado por } \\
\text { detritos em relação a } \\
\text { ausência da } \\
\text { vestimenta de } \\
\text { proteção do tronco }\end{array}$ & 30 & Uso adequado do EPI \\
\hline
\end{tabular}

Fonte: Autores, 2020. 
Com a obtenção do RPN (risk priority number) foi possível organizar os modos de falhas por ordem de prioridade, do mais arriscado ao menos arriscado. Para serviço de limpeza feito com roçadeira manual a falha do sistema de segurança adequado ao equipamento teve o maior RPN de 210, também o maior RPN geral, seguido do modo de falha Acidente de trânsito tendo como causa não-sinalização no trecho da obra obteve o RPN de 108. Para o serviço de Corte de pavimento asfáltico onde a causa básica da falha foi o local de trabalho frequentado por terceiros com RPN 96. As maiores falhas seguintes correspondem a não utilização dos EPI's. Mediante isso, nota-se que os resultados tem alto potencial de falha, colocando a vida dos colaboradores em risco durante os processos, o que reforça a importante das ações preventivas, evitando assim futuros acidentes.

\section{CONCLUSÃO}

Para que o processo ocorra de forma estável é de suma importância a segurança e saúde do colaborador, mediante isso, o quadro de funcionários deve passar por treinamento e qualificação para exercer sua função em segurança e o empregador disponibilizar ferramentas de qualidade para melhorar o processo. Os treinamentos são fundamentais para um correto funcionamento do sistema de gestão, porque assim é posto na mente do trabalhador a correta execução da tarefa bem como o manuseio dos equipamentos e máquinas. Nos treinamentos, o trabalhador aprende a importância do uso de EPI e aprende a observar corretamente os EPC e respeitar seus avisos.

É de máxima importante a fiscalização durante o processo. Com relação ao uso de equipamentos de segurança, a presença de técnico ou engenheiro de segurança responsável é imprescindível, pois identifica-se que os equipamentos de proteção eram entregues aos trabalhadores e, já que não havia fiscalização frequente, os equipamentos não foram utilizados de forma correta ou, em algumas situações, não foram utilizados de forma alguma. É importante ressaltar a aplicação das NR's, pois elas fornecem as informações necessárias para que um projeto tenha as mínimas condições de proteção e bem estar para a equipe de trabalho.

Assim, conclui-se que os métodos APR e FMEA auxiliam na elaboração de um planejamento da melhor maneira possível e devem ser feitas antes do início das atividades. Esses métodos visualizam as potenciais falhas e informam os locais onde a probabilidade de prejuízo é maior.

\section{REFERÊNCIAS}

Bucasio, E. et al., (2005). Transtorno de estresse pós-traumático como acidente de trabalho em um bancário: relato de um caso. Revista de Psiquiatria do Rio Grande do Sul, 27(1), 8689.

Buodo, G. et al., (2011). Assessment of cognitive functions in individuals with post-traumatic symptoms after work-related accidents. Journal of anxiety disorders, 25(1), 64-70.

Cavaignac, A. L. de O., \& Uchoa, J. G. L. (2018). Obtaining FMEA's indices for occupational safety in civil construction: a theoretical contribution. Brazilian Journal of Operations \& Production Management, 15(4), 558-565. 
Cavaignac, A. L. de O., \& Forte, L. L. N. (2018). Utilização do FMEA para priorização de risco ocupacional: uma nova abordagem direcionada a construção civil. Brazilian Journal of Production Engineering-BJPE, 132-149.

Transporte Rodoviário: desempenho do setor, infraestrutura e investimentos. - Brasília: CNT, 2017.

http://cms.cnt.org.br/Imagens\%20CNT/PDFs\%20CNT/Estudos\%20CNT/estudo_transporte_r odoviario_infraestrutura.pdf

Galon, T., Marziale, M. H. P., \& Souza, W. L. de. (2011). A legislação brasileira e as recomendações internacionais sobre a exposição ocupacional aos agentes. Revista Brasileira de Enfermagem, 64(1), 160-167.

Iriart, J. A. B. et al., (2008). Representações do trabalho informal e dos riscos à saúde entre trabalhadoras domésticas e trabalhadores da construção civil. Ciência \& Saúde Coletiva, 13(1), 165-174.

Laurenti, R., Villari, B. D., \& Rozenfeld, H. (2012). Problemas e melhorias do método FMEA: uma revisão sistemática da literatura. Pesquisa \& Desenvolvimento Engenharia de Produção, 10(1), 59-70.

Mcdermott, R. E., Mikulak, R. J., \& Beauregard, M. R. (2009). FMEA. New York: Taylor \& Francis Group.

Menezes, Afonso Henrique Novaes et al., (2019). Metodologia científica: teoria e aplicação na educação a distância. Universidade Federal do Vale do São Francisco, Petrolina-PE.

Ministério da Saúde do Brasil (2001). Doenças relacionadas ao trabalho: Manual de procedimentos para os serviços de saúde. Ministério da Saúde do Brasil, Organização PanAmericana da Saúde no Brasil. Brasília: Ministério da Saúde do Brasil.

Mota, C. P. A., \& Oliveira, C. A. L. de (2019). Avaliação de risco ocupacional em obras de pequeno porte de unidades unifamiliares com aplicação do FMEA: uma investigação sobre trabalho em altura e escavações. Brazilian Journal of Production Engineering - BJPE, 25-35.

Novara, C. et al. (2009). Integrated assessment of emotional distress after work-related accidents. Stress and Health: Journal of the International Society for the Investigation of Stress, 25(2), 195-204.

Peixoto, C. H. Vantagens em investir em saúde e segurança do trabalho.

Salim, C. A. (2003). Doenças do trabalho: exclusão, segregação e relações de gênero. São Paulo em perspectiva, 17(1), 11-24.

Santana, V. S., \& Oliveira, R. P. (2004). Saúde e trabalho na construção civil em uma área urbana do Brasil. Cadernos de Saúde Pública, 20, 797-811.

Stamatis, D. H. (2003). Failure mode and effect analysis: FMEA from theory to execution. Quality Press.

Uchoa, J. G. L. et al., (2019). FMEA method application based on occupational risks in the construction industry on work at height: A theoretical contribution. Int J Adv Eng Res Sci, 6(10), 261-278.

Yin, R. K. (2015). Estudo de Caso: Planejamento e métodos. Bookman editora. 